\title{
Convergence Blockchain, AI en IoT
}

\section{Jan Veuger*}

Schools of Finance \& Accounting, Creative Technology and School of Governance, Netherlands

\section{Opinion}

The movement towards each other of different technologies such as Blockchain, Artificial

ISSN: 2576-8840

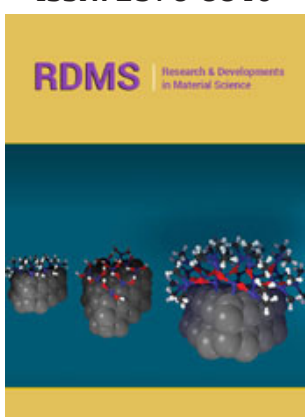

*Corresponding author: Jan Veuger, Professor Blockchain Saxion University of Applied Sciences Enschede The Netherlands, Schools of Finance \& Accounting, Creative Technology and School of Governance, Law and Urban Development, Netherlands

Submission: 酸 October 04, 2019

Published: 眥 October 15, 2019

Volume 12 - Issue 1

How to cite this article: Jan Veuger. Convergence Blockchain, AI en IoT. Res Dev Material Sci. 12(1).RDMS.000777.2019. DOI: 10.31031/RDMS.2019.12.000777

Copyright@ Jan Veuger, This article is distributed under the terms of the Creative Commons Attribution 4.0 International License, which permits unrestricted use and redistribution provided that the original author and source are credited. Intelligence and Internet of Things, among others, will be an impactful combination of security, interconnection and autonomy on which current processes will run completely differently [1].

A combination of not only Blockchain, AI and IoT technologies, but also other technologies, will shape a different economy in both the digital and physical world. New business models will emerge for companies as we see with Amazon, Cool Blue and bol.com as examples. There are already many overlaps between different technologies ${ }^{1}$ as for example with the Beijing Daxing International Airport in China [2] using facial recognition with AI and data on a Blockchain (Figure 1).

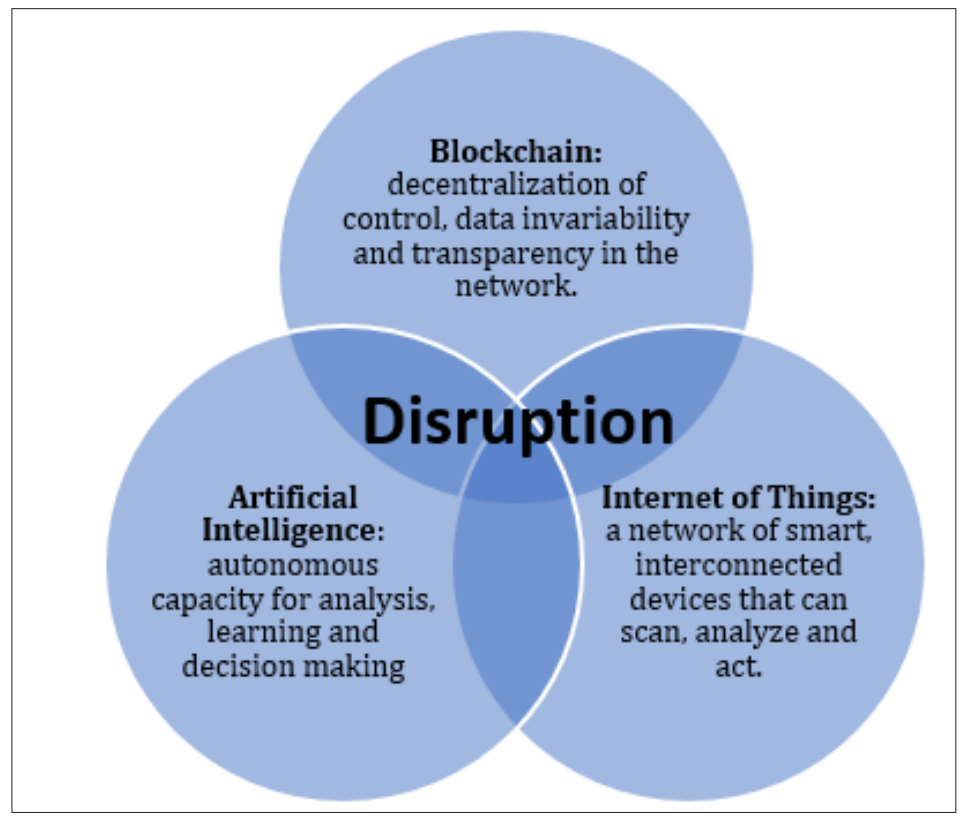

Figure 1: The individuals and disruption between Blockchain, Artificial Intelligence and Internet of Things.

Blockchain enables a large number of computers to perform their tasks together and to store information in a decentralized, unchanging and universally accessible way.

Internet of Things provides seamless interconnectivity between different everyday objects, equipped with sensors, microprocessors and transducers to create a network that can independently perceive and collect data, analyse it continuously and perform programmed tasks.

Artificial Intelligence gives full autonomy in analyzing data, making decisions and taking action on computers or other smart devices. AI can be replicated under certain circumstances and even exceed human computational and cognitive capabilities. Organizations use AI to automate primarily repetitive, routine processes that may require large amounts of data processing and fast decision making based on pure logic. 


\section{The convergence of the blockchain, artificial intelligence and internet of things}

Joshi [1] argues that the convergence of Blockchain, Ai, and IoT can enable organizations to maximize the benefits of each of these technologies while minimizing the risks and limitations associated with them. IoT networks often include many smart devices that collect data from their environment and can take actions based on it, among other things. However, data can also normally be hacked as we regularly hear in the media, but with data on a Blockchain this is virtually impossible.

For example, a proven convergence of Blockchain, $\mathrm{AI}^{2}$ and IoT is the algorithm ${ }^{3}$ of Fujitsu ${ }^{4}$, a Japanese electronics manufacturer, to measure the heat stress level of employees [1]. This algorithm monitors all data and can determine correlations to track the health of people in healthcare on a Blockchain database. Healthcare on its own is a high-tech and an intensive information environment. Because of this complexity, there can be a lot of ambiguity in insights and Blockchain with structured data can properly secure personal data in relation to privacy. With smart contracts built on Blockchain, premiums can be paid and financial settlements with health insurers can be arranged automatically.
The eventual convergence of various technologies with Blockchain as the cement between them is not yet in the fifth phase of the Gartner Hype Cycle. Since 2015 Blockchain has been much in the spotlight as a hype, in 2020 it is starting to develop more and more. The transformation in the fifth phase of the Gartner Hype Cycle is likely to take place in the coming years. In it, practical examples will become the ambassadors for further future developments and bring about convergence between different technologies.

\section{Acknowledgement}

This article of the date 01.02.2022 is a new version as compared to the published version on October 15, 2019 and submission October 04,2019 by which the article does justice to the source of Joshi (2018) among others and other sources used earlier which were not included in the previous article but were included in the working paper of that time which is extremely clear and with this revised article in an integer manner the error has therefore been rectified. This article is peer-reviewed.

\section{References}

1. Joshsi N (2018) What happens when blockchain, IoT, and AI convergence!

2. Veuger J (2020) Blockchain convergentie. Saxion UAS, Netherlands.

1 https://www.odyssey.org/

2 https://www.tno.nl/nl/tno-insights/artikelen/artificial-intelligence-angst-verlangen-en-toepassing/

3 https://www.fujitsu.com/cn/en/about/resources/news/press-releases/2019/frdc-0222.html

4 https://www.computable.nl/artikel/nieuws/security/6765432/250449/fujitsu-komt-met-nieuwe-handpalmidentificatie.html 